\title{
Pocket Doppler and vascular laboratory equipment yield comparable results for ankle brachial index measurement Saskia PA Nicolaï ${ }^{1}$, Lotte M Kruidenier ${ }^{1}$, Ellen V Rouwet ${ }^{1}$, Liliane Wetzels- Gulpers $^{2}$, Constantijn AM Rozeman ${ }^{2}$, Martin H Prins ${ }^{3}$ and Joep AW Teijink*1
}

\begin{abstract}
Address: ${ }^{1}$ Department of Surgery, Atrium medical center, Henri Dunantstraat 5, 6419 PC Heerlen, the Netherlands, ${ }^{2}$ Department of Clinical Neurophysiology/non-invasive vascular lab, Atrium medical center, Henri Dunantstraat 5, 6419 PC Heerlen, the Netherlands and ${ }^{3}$ Department of Epidemiology, Maastricht University/KEMTA, PO Box 616, 6200 MD Maastricht, the Netherlands

Email: Saskia PA Nicolaï - exitpad@gmail.com; Lotte M Kruidenier - 1.kruidenier@gmail.com; Ellen V Rouwet - erouwet@hotmail.com; Liliane Wetzels-Gulpers - lgs01@atriummc.nl; Constantijn AM Rozeman - crn01@atriummc.nl; Martin H Prins - Mh.prins@EPID.unimaas.nl; Joep AW Teijink* - j.teijink@atriummc.nl

* Corresponding author
\end{abstract}

Published: 7 October 2008

BMC Cardiovascular Disorders 2008, 8:26 doi:10.1186/1471-2261-8-26

This article is available from: http://www.biomedcentral.com/I47|-226I/8/26

(C) 2008 Nicolaï et al; licensee BioMed Central Ltd.

This is an Open Access article distributed under the terms of the Creative Commons Attribution License (http://creativecommons.org/licenses/by/2.0), which permits unrestricted use, distribution, and reproduction in any medium, provided the original work is properly cited.
Received: 3 April 2008
Accepted: 7 October 2008

\begin{abstract}
Background: The ankle brachial index $(A B I)$ is a well-established tool for screening and diagnosis of peripheral arterial disease (PAD). In this study we assessed the validity of $A B I$ determination using a pocket Doppler device compared with automatic vascular laboratory measurement in patients suspected of PAD.
\end{abstract}

Methods: Consecutive patients with symptoms of PAD referred for $A B I$ measurement between December 2006 and August 2007 were included. Resting ABI was determined with a pocket Doppler, followed by $A B I$ measurement with automatic vascular laboratory equipment, performed by an experienced vascular technician. The leg with the lowest $A B I$ was used for analysis.

Results: From 99 patients the mean resting $A B I$ was 0.80 measured with the pocket Doppler and 0.85 measured with vascular laboratory equipment. A Bland-Altman plot demonstrated great correspondence between the two methods. The mean difference between the two methods was $0.05(\mathrm{P}<.00 \mathrm{I})$. Multivariate linear regression analysis showed no dependency of the difference on either the average measured $\mathrm{ABI}$ or affected or unaffected leg.

Conclusion: Since the small, albeit statistically significant, difference between the two methods is not clinically relevant, our study demonstrates that $A B I$ measurements with pocket Doppler and vascular laboratory equipment yield comparable results and can replace each other. Results support the use of the pocket Doppler for screening of PAD, allowing initiation of cardiovascular risk factor management in primary care, provided that the equipment operator is experienced.

\section{Background}

The ankle brachial index (ABI) is useful in the diagnosis of peripheral arterial disease (PAD). With a sensitivity and specificity of $90 \%$ and $98 \%$, respectively, ABI is especially helpful in establishing lower extremity PAD [1,2]. The ABI has become increasingly important as a screening tool for identification of patients with asymptomatic PAD [3], which is an independent marker for adverse cardiovascu- 
lar outcome [4]. A patient with a low ABI has a 5.5-fold increased risk of cardiovascular death and a 2.5 -fold higher risk of coronary artery disease and of stroke [5]. Current guidelines recommend initiation of secondary prevention measures in all patients with a screening $\mathrm{ABI}$ value $<0.9$ and treatment of atherosclerosis risk factors [3]. Given the importance of the ABI as a predictor of cardiovascular disease and mortality [6], accurate determination of the $\mathrm{ABI}$ is crucial.

Equipment used to measure arm and ankle pressures differs between the primary care setting, outpatient clinics, and the vascular laboratory setting. Arm and ankle pressures in primary care and in outpatient clinics are usually measured with a pocket Doppler device. In vascular laboratory settings, these measurements are performed with automatic vascular laboratory equipment. Although the pocket Doppler method is widely used, comparisons of this method with vascular laboratory equipment have been limited. A recent study compared the ABI measurements of 30 patients with both types of equipment [7]. The pocket Doppler measurement was performed by a nurse, while the measurement in the vascular laboratory was performed by a vascular technologist, and the two health care providers had different levels of expertise in performing ABI measurements. The aim of this study was to compare pocket Doppler ABI measurements with automatic measurements performed in a vascular laboratory, with the procedures being performed by observers with equal levels of expertise and to determine if there are intrinsic differences in the results obtained with these two devices.

\section{Methods}

Ninety nine consecutive patients suspected of PAD who had been referred to the vascular laboratory of our hospital for an ABI measurement between December 2006 and August 2007 were included in this study. Informed consent was obtained and the study was approved by the medical ethical committee of the Atrium medical center Parkstad.

For valid comparisons of $A B I$ measurements performed by pocket Doppler and with laboratory equipment, both measurements were conducted on the same day in the vascular laboratory. For both methods, brachial pressures were measured bilaterally, and were repeated if the difference was $>10 \mathrm{~mm} \mathrm{Hg}$ between the two arms. Ankle pressures were determined with cuffs placed proximal to the malleoli. Following a 15 minute resting period, systolic blood pressures (SBP) in the brachial, dorsal pedal, and posterior tibial arteries were determined in a supine position with a pocket Doppler device (Doppler MD2, Huntleigh Healthcare, Cardiff, United Kingdom) by a trained vascular laboratory professional. Brachial and ankle pressures were measured with a sphygmomanometer cuff which was inflated and deflated manually. The first audible signal of the first ventricular systole was used to identify the SBP at each location. The ABI was calculated by dividing the highest systolic ankle pressure (either posterior tibial or dorsal pedal) in each leg by the highest systolic brachial pressure $[8,10]$. Then, all measurements were repeated by a second vascular technician, blinded to the previous results, using laboratory equipment (VasoGuard System XP84 (1999), Scimed, Bristol, United Kingdom). Sphygmomanometer cuffs used to measure brachial and ankle pressures inflated and deflated automatically by pressing a button. The SBP cutoff points of all arteries were defined as the systolic upstroke of the first arterial waveform. At the first characteristic arterial sound and at the simultaneous appearance of the first arterial waveform, the monitor screen was frozen, and the SBP cut-off point was defined by precise retrospective positioning of an adjustable marker line (Table $1)$.

\section{Statistic evaluation}

$\mathrm{ABI}$ measurements for each leg of the same patient are probably correlated since atherosclerosis is a generalised disease. Therefore, we used the lower ABI of both legs of each patient for analyses. The ABI values obtained from the pocket Doppler and from the vascular laboratory were averaged. The leg affected with PAD was defined as a leg with an $\mathrm{ABI}<0.9$. Differences between measurements were assessed with a one-sample Student's $t$-test. Multivariate linear regression analysis assessed the dependency of the observed difference between the two measurements and the average measured ABI for the affected and unaffected legs. Due to ethical considerations, intra arterial blood pressures were not performed and a Bland-Altman

Table I: Comparison of pocket Doppler and vascular laboratory measurement of brachial and ankle blood pressures

\begin{tabular}{lll}
\hline & Pocket Doppler & Vascular laboratory equipment \\
\hline Probe & $8 \mathrm{MHz}$ & $8 \mathrm{MHz}$ \\
Cuff inflation/deflation & Manually & Automatically \\
SBP cut-off point & - Audible signal & $\bullet$ Visual and audible signal \\
& - View the manometer at the time of the first sound & $\bullet$ Adjustable line placed on the monitor \\
& - Rapid response with immediate determination of the cut-off point & $\bullet$ Line is precisely positioned retrospectively \\
\hline
\end{tabular}


plot was used to visualise agreement between the two methods [9]. Statistical analysis was performed with SPSS version 14.0 for Windows.

\section{Results}

Characteristics of the study population are presented in Table 2. The mean age of the 99 participating patients was 65.0 years. Characteristics of the study population are presented in table 2. In total, 56 legs were diagnosed with PAD, (23 right legs and 33 left legs). The mean ABI of the 99 patients was 0.80 (SD 0.25) as measured with the pocket Doppler and 0.85 (SD 0.25) as measured with vascular laboratory equipment. Subtraction of the pocket Doppler result from the automatic vascular laboratory equipment result yielded a mean difference of 0.05 (SD $0.09)$, a value that was statistically significant $(P<.001)$. Multivariate linear regression analyses showed no dependency of the difference on the average measured ABI $(\mathrm{P}=.187)$ or whether the measurements were performed on affected or unaffected legs $(P=.235)$.

The two methods were compared by a Bland-Altman plot (Figure 1) which depicts the average ABI as determined by the two measurements across the difference between the pocket Doppler and the automatic ABI measurement for each leg. The Bland-Altman analysis confirmed that the data obtained by the two procedures was virtually the same.

\section{Discussion}

This study shows that the ABI values determined by a simple pocket Doppler device and by automatic vascular laboratory equipment are interchangeable. In view of the importance of the ABI in detecting patients with atherosclerosis, our study supports the use of the easily accessible and applicable Doppler device for the screening and diagnosis of PAD, thus permitting the initiation of cardiovascular risk factor management in the primary care practice.

The good clinical interchangeability between ABI assessment with pocket Doppler and automatic vascular laboratory equipment was elegantly demonstrated by a BlandAltman plot. However, ABI, as measured by pocket Doppler, tended to be consistently lower, independent of the

Table 2: Clinical characteristics of the study population

\begin{tabular}{lc}
\hline & Analysed population $\mathrm{n}=99$ \\
\hline Men - n (\%) & $60(60.6)$ \\
Age (years) - mean (SD) & $65.0(12.2)$ \\
BMI - mean (SD) & $26.6(3.9)$ \\
Hypertension - n (\%) & $72(72.7)$ \\
Diabetes Mellitus - $\mathrm{n}(\%)$ & $27(27.3)$ \\
\hline
\end{tabular}

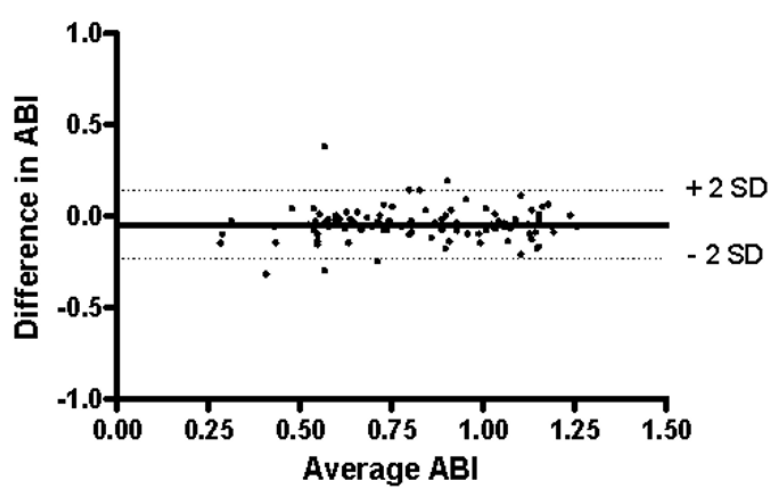

\section{Figure I}

Bland-Altman plot. Bland-Altman plot: The average $A B I$ of pocket Doppler and vascular laboratory equipment plotted against the difference in $A B I$ of both measurements. $(n=99)$.

average of the measured $\mathrm{ABI}$ and whether measurements were obtained from the affected or the unaffected leg. Although the minor, albeit statistically significant, difference in ABI of 0.05 is not considered to be clinically relevant [10], it may be important in the epidemiological context. In larger studies, ABI values close to the cut off point of 0.9 could influence the reported prevalence of PAD [11], and affect the determinations of sensitivity and specificity of the ABI measurement for the identification of high risk patients. An additional study on a larger population is required to resolve this problem.

The small difference in ABI between both methods may relate to the method of determination of SBP cut-off points and cuff in- and deflation. With the pocket Doppler, SBP is recorded from the sphygmomanometer simultaneously with the first audible signal, which can be influenced by human auditory limitations as well as by a slow response to the rapidly occurring audible signal. Most laboratory equipment automatically visualises the Doppler signal output with spectral analysis and displays the entire frequency and amplitude of the Doppler signal on the monitor [12]. The screen is frozen as the first arterial waveform is displayed and is accompanied by the audible signal. Subsequently, an adjustable line is placed precisely at the systolic upstroke of the first arterial waveform. Other artefacts including slight movements of the hand holding the Doppler device during manual inflation and deflation, alterations in the position or angle of the device, and variations in the amount of pressure can affect the quality of the Doppler signal, and consequently the SBP measurement [13].

In general, screening for PAD by $\mathrm{ABI}$ and thus, screening for atherosclerosis in peripheral arteries of the leg as a 
reflection of generalised atherosclerosis is highly encouraged. However, we suggest that clinical judgement must be used in the interpretation of $A B I$ values determined by pocket Doppler. Diabetes or longstanding renal failure medial calcinosis could lead to calcified arteries which may be inadequately compressed by the sphygmomanometer cuff, leading to falsely elevated ankle pressures. Referral to a vascular laboratory for the measurement of systolic toe pressures or additional vascular imaging is essential for adequate determination of the vascular status of these patients [10].

Furthermore, an experienced operator is mandatory for accurate determination of the ABI, as previously indicated by the positive influence of experience and training on the reproducibility of the ABI measurement $[14,15]$. Ray et al. demonstrated that inexperienced doctors performed $\mathrm{ABI}$ measurements less reliably than their trained counterparts [16]. In the present study, all vascular technicians were trained and experienced. Since the pocket Doppler method is highly operator dependent, it is particularly important that medical personnel is adequately trained in the acquisition of data using the pocket Doppler device so that $\mathrm{ABI}$ assessment can be widely applicable in primary care practice. However, the advised methods reported in the literature vary for the performance and the calculation of $A B I$ measurement $[10,12,17]$. Ideally, guidelines consistent with the method of measurement and calculation of the ABI should be established. Indeed, this instruction could be the basis for structured training programmes for medical personnel to develop this expertise. The present study shows that the pocket Doppler and automatic vascular laboratory equipment measurements of the $\mathrm{ABI}$ are interchangeable in patients suspected of PAD. The validity of pocket Doppler ABI measurement in a screening setting could be a subject of future studies.

\section{Conclusion}

Pocket Doppler assessment was demonstrated to be a practical tool for reliable and quick evaluation of the vascular status of a patient. This provides a useful tool for the investigation of patients with lower limb pain, and enables the targeted referral of patients with symptomatic PAD to the vascular specialist. Even more importantly, it introduces the opportunity for atherosclerosis screening and cardiovascular risk management in asymptomatic patients to reduce cardiovascular morbidity and mortality.

\section{Competing interests}

The authors declare that they have no competing interests.

\section{Authors' contributions}

SN carried out the statistical analysis and was responsible for writing the drafts of the manuscript. LK contributed to the preparation of the manuscript and the statistical analysis. EV reviewed the manuscript critically. LW carried out the $\mathrm{ABI}$ measurements and contributed to the preparation of the manuscript. CR participated in development of the concept and design of the study and reviewed the manuscript. MH contributed to the concept and design of the study and to the statistical analysis. JT participated in the conception and design of the study and critically reviewed the manuscript.

\section{Acknowledgements}

We would like to thank the vascular technicians of the non-invasive vascular lab for performing the $\mathrm{ABI}$ measurements.

\section{References}

I. Yao ST, Hobbs JT, Irvine WT: Ankle systolic pressure measurements in arterial disease affecting the lower extremities. $\mathrm{Br}$ J Surg 1969, 56:676-9.

2. Ouriel K, McDonnell AE, Metz CE, Zarins CK: Critical evaluation of stress testing in the diagnosis of peripheral vascular disease. Surgery 1982, 91:686-93.

3. Hirsch AT, Haskal ZJ, Hertzer NR, Bakal CW, Creager MA, Halperin JL, et al:: ACCIAHA Guidelines for the management of patients with peripheral arterial diseases (lower extremity, renal, mesenteric and abdominal aortic): a collaborative report from the American Association for Vascular Surgeryl Society for Vascular Surgery, Society for Cardiovascular Angiography and Interventions, Society for Interventional Radiology, Society for Vascular Medicine and Biology, and the American College of Cardiology/American Heart Association Task Force on Practice Guidelines (Writing Committee to develop guidelines for the management of patients with peripheral arterial disease). Circulation 2005, 2 I :e463-e654.

4. Fowkes FG, Murray GD, Butcher I, Heald CL, Lee RJ, Chambless LE, et al:: Ankle brachial index combined with Framingham Risk Score to predict cardiovascular events and mortality: a meta-analysis. JAMA 2008, 300:197-208.

5. Doobay AV, Anand SS: Sensitivity and specificity of the anklebrachial index to predict future cardiovascular outcomes: a systematic review. Arterioscler Thromb Vasc Biol 2005, 25: I463-9.

6. Criqui MH, Langer RD, Fronek A, Feigelson HS, Klauber MR, McCann TJ, et al.: Mortality over a period of 10 years in patients with peripheral arterial disease. New Engl J Med 1992, 326:38I-6.

7. Bonham PA, Cappuccio M, Hulsey T, Michel Y, Kelechi T, Jenkins C, et al.: Are ankle and toe brachial indices (ABI-TBI) obtained by a pocket Doppler interchangeable with those obtained by standard laboratory equipment? J Wound Ostomy Continence Nurs 2007, 34:35-44.

8. Atsma F, Bartelink ML, Grobbee DE, Schouw YT van der: Best reproducibility of the ankle-arm index was calculated using Doppler and dividing highest ankle pressure by highest arm pressure. J Clin Epidemiol 2005, 58: 1282-8.

9. Bland JM, Altman DG: Statistical methods for assessing agreement between two methods of clinical measurement. Lancet 1986, I:307-10.

10. Norgren L, Hiatt WR, Dormandy JA, Nehler MR, Harris KA, Fowkes FG: Inter-Society Consensus for the Management of Peripheral Arterial Disease (TASC II). J Vasc Surg 2007, 45(Suppl S):S5-67.

II. Lange SF, Trampisch HJ, Pittrow D, Darius H, Mahn M, Allenberg JR, et al: Profound differences of different methods for determination of the ankle brachial index on the prevalence estimate of peripheral arterial disease. BMC Public Health 2007, 7:147.

12. Bartelink MLSH, Boutens EJ, Hooi JD, Kaiser V, Boomsma LJ: NHGstandaard perifeer arterieel vaatlijden (eerste herziening). Huisarts Wet 2003, 46:848-58.

13. Cronenwett JL: The vascular laboratory. 5th edition. Edited by: Rutherford RB. Philadelphia: Saunders; 2000:127-39.

14. Matzke S, Franckena M, Alback A, Railo M, Lepantalo M: Ankle brachial index measurements in critical leg ischaemia - the 
influence of experience on reproducibility. Scand / Surg 2003, 92:144-7.

15. Kaiser V, Kester AD, Stoffers HE, Kitslaar PJ, Knottnerus JA: The influence of experience on the reproducibility of the anklebrachial systolic pressure ratio in peripheral arterial occlusive disease. Eur J Vasc Endovasc Surg 1999, 18:25-9.

16. Ray SA, Srodon PD, Taylor RS, Dormandy JA: Reliability of ankle:brachial pressure index measurement by junior doctors. Br J Surg 1994, 81: 188-90.

17. Greenland P, Abrams J, Aurigemma GP, Bond MG, Clark LT, Criqui $\mathrm{MH}$, et al:: Prevention Conference V: Beyond secondary prevention: identifying the high-risk patient for primary prevention: noninvasive tests of atherosclerotic burden: Writing Group III. Circulation 2000, I I I(I):EI6-22.

\section{Pre-publication history}

The pre-publication history for this paper can be accessed here:

http://www.biomedcentral.com/1471-2261/8/26/prepub

Publish with Bio Med Central and every scientist can read your work free of charge

"BioMed Central will be the most significant development for disseminating the results of biomedical research in our lifetime. "

Sir Paul Nurse, Cancer Research UK

Your research papers will be:

- available free of charge to the entire biomedical community

- peer reviewed and published immediately upon acceptance

- cited in PubMed and archived on PubMed Central

- yours - you keep the copyright 